\title{
Libertadoras en tiempos de revolución. La participación de las mujeres en la independencia del Perú y América Latina
}

\section{Liberators in times of revolution. The participation of women in the independence of Peru and Latin America}

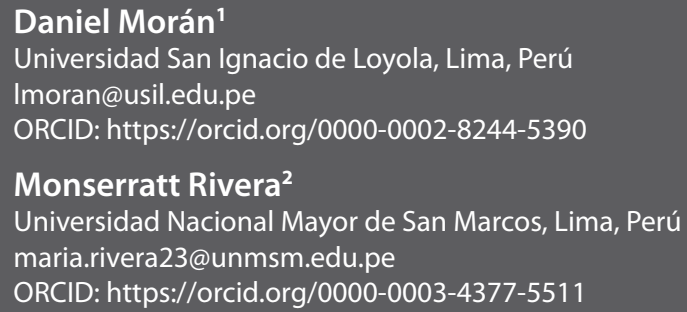

Citar como: Morán, D. y Rivera, M. (2021). Libertadoras en tiempos de revolución. La participación de las mujeres en la independencia del Perú y América Latina. Desde el Sur, 13(1), e0013

\section{RESUMEN}

Tras la llegada del bicentenario a los distintos países de América Latina, nuestra investigación tiene como objetivo principal resaltar la participación de la mujer en las independencias de sus respectivas naciones, con el fin de conmemorar estas fechas y poner de relieve su rol como sujeto histórico. De este modo, se tomará como punto de partida lo expresado por la historiografía reciente sobre las acciones de las heroínas de la independencia, tanto en su labor de espías del ejército patriota o arriesgando su vida en el campo de batalla. Así, se realizará este ensayo con una perspectiva de género, deteniéndose en figuras importantes como Manuela Sáenz, María Parado de Bellido, Policarpa Salavarrieta, Francisca Zubiaga, Rosa Campusano;

\footnotetext{
1 Docente investigador Renacyt-Concytec de la Facultad de Educación de la Universidad San Ignacio de Loyola, Perú. Doctor en Historia por la Universidad de Buenos Aires, magíster en Historia en la Universidad de General San Martín en Argentina y licenciado en Historia en la Universidad Nacional Mayor de San Marcos, Perú. Autor de artículos sobre la temática de las guerras de independencia y la prensa en América Latina, en revistas indexadas en Scopus, WOS y SCiELO.

2 Estudiante de Historia de la Facultad de Ciencias Sociales de la Universidad Nacional Mayor de San Marcos, Perú. Su campo de investigación abarca la historia de género y la participación de la mujer en el siglo XIX peruano.
} 
y además se señalarán las acciones de distintos colectivos de mujeres, cuyos nombres no conocemos, no obstante que sus acciones fueron relevantes para la independencia del Perú y de América Latina.

\section{PALABRAS CLAVE}

Mujeres, independencias, perspectiva de género, América Latina, Perú

\section{ABSTRACT}

In the wake of the arrival of bicentennial anniversaries in different countries of Latin America, our research aims to highlight the participation of women in the independence of their respective nations, in order to commemorate those dates while highlighting women's roles as historical subjects. To this end, we take as a starting point that which has been expressed in recent historiographies regarding the actions of the heroines of independence, both in their work as spies for the patriot army, or while risking their lives on the battlefield. Thus, this essay adopts a gender perspective, focusing on important figures such as Manuela Sáenz, María Parado de Bellido, Policarpa Salavarrieta, Francisca Zubiaga and Rosa Campusano. Furthermore, the actions will be addressed of different groups of women whose names we do not know, despite the relevance of their actions in the struggle for independence in Peru and Latin America.

\section{KEYWORDS}

women, independence, gender perspective, Latin America, Peru

\section{Introducción}

La historia de la independencia y de sus héroes ha sido muy bien narrada en la historiografía peruana y sudamericana, y cuenta con descripciones tan objetivas - como sea posible en nuestro campo de investigación- de los héroes de las guerras que se libraron o de los libertadores. Tenemos conocimiento sobre los tratados firmados, los planes que llevaron a cabo, su papel en la guerra, la inteligencia y valentía masculina, entre otras características que contribuyen a destacar la participación activa y relevancia de los «grandes hombres» protagonistas del proceso independentista (Morán y Pérez, 2020; San Martín, 2020). 
Sin embargo, no nos animaríamos a decir lo mismo sobre el conocimiento de la participación de las mujeres en las guerras de independencia, porque la producción historiográfica sobre ellas y sus acciones, durante mucho tiempo, en su mayoría tenía un elevado componente subjetivo en comparación con lo escrito acerca de los hombres de su época (Angulo, 2020; Hortal, 2017). En este sentido, nuestra investigación buscará brindarnos algunas luces respecto a las acciones de las mujeres de la independencia de nuestro continente, y resaltar sobre todo su accionar político y militar. De este modo, evitaremos que se piense a las mujeres en este contexto como sujetos complementarios en un hecho histórico y demostrar que tenían sus propios planes para contribuir a la lucha independentista (Rosas, 2019; Morán, 2018; Morán, 2009).

Es importante señalar que existen contribuciones importantes sobre la participación femenina en la independencia de nuestro continente, como la de Ana Belén García (2011), quien señala que este escenario de lucha y revolución por la libertad de los pueblos americanos fue aprovechado por las mujeres para intervenir en la vida pública y transgredir las barreras sociales. Asimismo, Sara Beatriz Guardia (2013) resalta que desde el tiempo colonial existió una exclusión de género, lo cual se prolongó hasta la independencia y la formación de las repúblicas; por lo tanto, las excluidas de la libertad eran las mujeres. La misma autora y otros especialistas en diversas publicaciones sobre el papel de la mujer en las guerras de independencia en América Latina insistieron en estos argumentos de la centralidad de las mujeres en estos tiempos de cambios y revolución (Guardia, 2014 y 2010).

Por otro lado, Montiel (2015) se pregunta si existe la posibilidad de narrar históricamente la independencia ponderando la participación de algunos protagonistas y dejando en el olvido a otros. Según él, eso es exactamente lo que sucede cuando se explora el rol de la mujer en este proceso. Además, Montiel considera que sin las mujeres —que, además de participar en el campo militar, asumieron las tareas de logística, sanidad, alimentación, propaganda, entre otras - la victoria no hubiera sido posible.

Para el caso del Perú, Susana Reisz (2015) destaca cómo en Huamanga surge un grupo de mujeres que se levantan en contra del poderío español en 1814 y que su actuación fue determinante para que los hombres se unieran y levantaran en armas también. Después de fracasar esta rebelión, ninguna de estas mujeres fue vista en la escena pública. Hace énfasis también en el protagonismo de otras peruanas como María Parado de Bellido, Tomasa Tito Condemayta y Micaela Bastidas. 
Precisamente, Guardia (2019) reconstruye de forma sistemática la trayectoria y participación de Micaela Bastidas en los movimientos sociales y en las rebeliones anticoloniales que darían origen tiempos después a las guerras de independencia en los Andes peruanos. En ese contexto, Rosas (2019) y otras investigadoras también han estudiado la historia de género y su ubicación del hogar al espacio público en el Perú. Asimismo, Morán y Aguirre (2013) reconocen que «es perceptible el papel medular que cumpliría la mujer en la vida privada, pública y en las decisiones políticas de los gobiernos».

Es así que, en las siguientes líneas, se mostrarán las principales acciones femeninas en el siglo XIX en la búsqueda de la emancipación de la Corona española por la ansiada libertad del continente. Además, nos detendremos brevemente en el caso de la mujer peruana. Todo esto debido a que ya no es viable escribir la historia sin mostrar a la mujer como agente del cambio histórico; por el contrario, anteriormente se encontraban interpretaciones que apuntaban a la invisibilidad femenina (Scott, 2012, citado en GarcíaPeña, 2016). En suma, el presente artículo tiene como objetivo poner en evidencia la figura femenina como sujeto histórico en el proceso de la independencia de sus respectivos países.

\section{Compromiso con la independencia}

Hemos escuchado muchas cosas respecto a las «amantes» de los libertadores, o al menos ese era el calificativo con el cual nos presentaban a estas mujeres, dejando de lado su compromiso con la independencia y centrando la atención en su vida privada. Es así que se les restaba mérito en su participación en este proceso. Según Martínez (2012), estos prejuicios hacia ellas pueden deberse al pensamiento de la época (p. 11), el cual consideraba que a las mujeres no les correspondía combatir, como tampoco combaten niños o ancianos, por más que se encontraran ejemplos de lo contrario. El orden natural de las cosas dictaba que las mujeres debían recibir protección por parte de sus acompañantes masculinos.

Sin embargo, existieron mujeres que se atrevieron a actuar en contra de este orden $y$, al igual que San Martín y Simón Bolívar, estuvieron intensamente involucradas en la lucha de la liberación de la monarquía española desde muy jóvenes. No obstante, hasta la actualidad no conocemos mucho de ellas y seguimos brindándole especial atención a las figuras masculinas (Ortemberg, 2011). De este modo, en las siguientes líneas hablaremos acerca de la actividad política femenina, así como del apoyo económico y logístico que brindaron a la causa independentista. 
Manuela Sáenz, en palabras de Boussingault, minerólogo francés que fue contratado por Bolívar para formar parte de un proyecto educativo en la Gran Colombia, era descrita como una mujer con actitudes masculinas, ya que luchaba en el campo de batalla y gozaba de un espíritu libertador, además de ser excéntrica y liberada. Con tal descripción, Boussingault daba a entender que el anhelo de emancipación de la monarquía española era una característica más propia de los hombres que de las mujeres; evidentemente Boussingault fue un hombre lleno de los prejuicios de su época. No obstante, Manuelita fue una figura fundamental en el apoyo económico y logístico a San Martín junto con otras mujeres de sociedad, dentro de las cuales se encontraba Rosa Campusano. Asimismo, fue archivista y secretaria personal de Simón Bolívar.

Dentro de sus Memorias (1985), Boussingault dedica un capítulo entero a contar la historia sobre cómo conoce a Sáenz en el salto de Tequendama, ubicado en Colombia. Vale resaltar que para ese momento Manuela ya había sido ascendida al grado de coronela y es así como se presenta ante él, vestida con uniforme militar, utilizando un bigote y montando su caballo. Por ello, su presencia en primera instancia resultó extraña para el francés, quien se refiere a Manuelita como «él», hasta que logró darse cuenta de que se encontraba frente a una mujer. «Estuvo encantadora y amable con cada uno de nosotros; habló del salto con entusiasmo: "Allá volveremos y pronto", decía. ¡Qué persona tan extraordinaria Manuelita! Qué de debilidades, de ligerezas, de valor y devoción a sus amigos. Se podría decir de ella: "es un amigo seguro, pero una amante infiel"» (Boussingault, 1985, p. 287).

Como podemos observar en la cita anterior, el minerólogo francés resalta que Sáenz podría ser un "gran amigo», hablando de esto en masculino, atribuyendo lo positivo en ella a una cualidad masculina. Mientras que, para describirla como mujer, en su condición de amante, hace referencia a algo negativo: la infidelidad. Y esta descripción tan solo se le ocurrió en el mismo día de haberla conocido, sin tener mayor conocimiento sobre ella. Además, menciona que la esclava de Manuela podría ser también su amante; luego señala que se trata de una suposición suya, ya que es algo que no puede comprobar de ninguna manera. Sin embargo, es importante darnos cuenta de cómo el actuar de las mujeres en ese contexto podía ser malinterpretado por los hombres de su sociedad, al relacionarse lo negativo con el actuar femenino, siempre poniéndolas en tela de juicio.

Por otro lado, Sáenz obtiene el grado de coronela, tras haber aceptado la invitación que se le hizo para participar en la batalla de Junín y Ayacucho. Luego de la última fue ascendida al cargo de coronela del 
Ejército colombiano. Además, Sáenz acostumbraba a pasar su tiempo en tertulias hasta altas horas de la noche, con compañía exclusivamente masculina y tomando algunas copas de sus bebidas favoritas, lo cual no era visto como algo apropiado en una señora respetable, dada la época de la cual fue parte.

Un hecho importante en el cual Sáenz fue protagonista ocurrió el 25 de setiembre de 1828, fecha del atentado contra la vida de Simón Bolívar cuando era presidente de la Gran Colombia. Este acontecimiento es señalado por Boussingault en sus Memorias.

Bolívar habitaba un entresuelo y los conjurados quisieron entrar allí, golpearon con fuerza y cuando iban a tumbar la puerta apareció Manuelita. Se buscó en vano porque ella, al escuchar el ruido, adivinó una conspiración e inmediatamente, con ayuda de una sábana atada a una ventana que daba sobre la calle, había hecho escapar al Libertador. Puede juzgarse cuál fue la sorpresa de los conjurados (Boussingault, 1985, p. 295).

El motivo de este atentado fue el reemplazo del vicepresidente Francisco de Paula Santander. Por ello, un grupo de sus seguidores ingresó al Palacio Presidencial con el objetivo de matar al caraqueño después de asesinar a todos los guardias. Bolívar logró huir del lugar por una ventana gracias a la ayuda de Manuela. Y fue ella quien se enfrentó a los conspiradores, ellos la tumbaron y le patearon la cabeza, ante lo cual Sáenz no dejaba de gritar: «Pero mátenme, cobardes, maten a una mujer». Este atentado se conoce bajo el nombre de Conspiración Septembrina y de ahí nace la famosa frase pronunciada por el Libertador hacia Sáenz tras encontrarse después de haberle salvado la vida: «Tú eres la libertadora del Libertador».

Manuela Sáenz desde muy joven tuvo presencia en el movimiento por la independencia que se gestaba. Su figura llegó a romper con los cánones que obligaban a las mujeres al sometimiento del orden patriarcal, es decir, que se mantengan en el espacio privado, ya que la esfera pública era netamente para varones. Su lucha contribuyó a la liberación de tres países: Ecuador, Perú y Colombia. Manuelita recibió la Orden del Sol por San Martín, en reconocimiento a su entrega en la lucha independentista $y$, como ya se mencionó, fue coronela del Ejército de la Gran Colombia.

Además, es conocido el hecho de cómo el vicepresidente de Colombia le aconseja a Bolívar que le quiten el título de coronela, ante lo cual el Libertador responde que un ejército se hace con héroes y que sería tonto degradarla. Se puede notar que Sáenz con su actuar incomodó a los hombres de su época. Fue una de las mujeres «vilipendiadas, censuradas y 
exiliadas por ser mujeres transgresoras y haber invadido los tradicionales poderes del hombre» (García, 2011, p. 41).

Sin embargo, la libertadora del Libertador no fue la única víctima del pensamiento patriarcal de la sociedad del siglo XIX. Muchas otras mujeres no se quedaron en el ámbito doméstico cumpliendo el rol de madre y esposa, y por decidir involucrarse en el proceso independentista atravesaron la misma situación y fueron juzgadas de igual manera:

Se las tildó de egoístas, autoritarias, ambiciosas y dominantes, descalificándolas por utilizar las armas a su alcance para conseguir sus objetivos políticos mientras que se alababa la decisión de los caudillos, sus aspiraciones de grandeza y el empleo de cualquier método para hacer triunfar sus ideales. Una vez más resurgió la subordinación a la que estaba sometida la mujer, dominada y no dominante, excluida además de la esfera pública, a la que se le permitió acceder solamente para colaborar en el triunfo del proceso independentista (García, 2011, p. 41).

Otra figura femenina cuya participación fue relevante para la independencia fue Rosa Campusano, amiga de Manuela Sáenz, conocida al igual que ella por un amorío, en este caso con el libertador argentino. Se le conoció como «la Protectora» dada su cercanía a San Martín. No obstante, su rol fue fundamental para la economía de la causa independentista, debido a que Campusano había financiado a los soldados realistas que se unían al Ejército Libertador proporcionándoles caballos y dinero. Además de ser una importante espía, hizo amistad con varios soldados realistas. Esto proporcionó a Campusano cierta cercanía a algunas autoridades españolas como el virrey La Serna. Todo lo que escuchaba en las reuniones de estos españoles era transmitido por ella misma posteriormente al Libertador.

Según lo que nos cuenta Ricardo Palma en sus Tradiciones peruanas (2007), Campusano llega a la capital peruana en 1817, cuando tenía tan solo 21 años, y rápidamente establece amistad con personas de la sociedad limeña. Del mismo modo, consiguió comunicarse con San Martín mediante cartas enviadas por ella desde que el Libertador pisó suelo peruano en 1820, cuando desembarcó en Paracas. Asimismo, la protectora organizaba tertulias en su casa y tenía como asistentes a figuras de la alta sociedad limeña simpatizantes de la causa patriota, entre las cuales se encontraban Sánchez Carrión y Mariátegui. A estas reuniones también acudía regularmente Manuela Sáenz.

En las siguientes líneas, veremos un pasaje de las Tradiciones peruanas, en donde Palma hace referencia a cómo Campusano conseguía información para comunicársela a los patriotas. 
Desde que San Martín desembarcó en Pisco, doña Rosa, que a la sazón tenía por amante oficial al general don Domingo Tristán, entabló activa correspondencia con el egregio argentino. Tristán y La Mar, que era otro de los apasionados de la gentil dama, servían aún bajo la bandera del rey, y acaso tuvieron en presencia de la joven expansiones políticas que ella explotara en provecho de la causa de sus simpatías. Decíase también que el virrey La Serna quemaba el incienso del galanteo ante la linda guayaquileña, y que no pocos secretos planes de los realistas pasaron así desde la casa de doña Rosa hasta el campamento de los patriotas en Huaura (Palma, 2007, p. 163).

Palma da a entender que todos los hombres caían rendidos ante los encantos de la protectora -incluso el mismo virrey - y que, gracias a esto, ella obtuvo la información necesaria para las tropas patriotas. Sin embargo, creemos también que es una descripción superficial sobre cómo una mujer podía aportar a una causa haciendo uso de su belleza física, ya que esto no hace más que contribuir al estereotipo de femme fatale de las espías, y le resta importancia a su astucia y valentía. Esto a largo plazo haría que su accionar durante el proceso independentista no sea considerado verdaderamente como patriota, sino como la actitud propia de una mujer inmoral o un ser con las «debilidades propias de su sexo», tal como escribió Palma. No obstante, Ricardo Palma, al igual que Boussingault, fue un hombre de su época.

Por otro lado, es conocido el hecho de que gracias a la astucia de Campusano un batallón realista completo se pasara a las filas patrióticas. Asimismo, es necesario resaltar que tanto Campusano como Sáenz difundían material propagandístico por las calles de la ciudad.

Ambas mujeres se convirtieron en las espías patriotas más audaces. Se vestían como tapadas y recorrían calles, plazas y mercados de la ciudad repartiendo propaganda independentista, que en las noches era pegada en las paredes. Fue Rosa quien influyó en el comandante realista Tomás de Heres para que él y sus 900 soldados del batallón Numancia se pasaran a las filas patriotas acantonadas en Huaura. Por sus actividades clandestinas y subversivas fue detenida por unos días, al igual que había sido detenida en 1818 tras ser denunciada ante la Inquisición por tener libros prohibidos. Sus amistades e influencias lograron liberarla (Diario Oficial El Peruano, 2019).

Rosa Campusano y su labor como espía patriótica fue determinante para el conocimiento de los movimientos militares de los realistas. Además, tenía poder de convencimiento sobre algunos hombres, al punto de hacerlos abandonar el ejército realista y unirse al bando patriótico. Su amistad con personas de la alta sociedad limeña le sirvió en el desarrollo 
de su labor. Si la apresaban, ellos movían sus influencias para liberarla. Fue una de las condecoradas con la Banda de Honor Blanca y Roja por San Martín. A pesar de todo esto, murió en la pobreza, pidiendo ayuda al gobierno peruano para subsistir. Pasó sus últimos días en la Biblioteca Nacional con 55 años de edad, y falleció en brazos del único hombre que se quedó con ella hasta el final: su hijo.

Estas mujeres no fueron valoradas en su época y fueron juzgadas bajo los prejuicios propios de una sociedad patriarcal. Algunos miembros conservadores de la sociedad limeña se molestaron cuando San Martín reconoció a Campusano con la Orden del Sol por su labor en la independencia. Manuela no tuvo mayor suerte, ya que después de la desintegración de la Gran Colombia fue expulsada. Fue aceptada por el Perú, se asentó en el puerto de Paita y subsistió con la venta de dulces y servicios de traducción a viajeros. Finalmente murió por difteria a los 60 años.

\section{Las mártires de la Independencia}

En este apartado la protagonista será la mujer mártir, quien con coraje y valentía contribuyó a la lucha por la independencia del Perú, hasta incluso dar la vida y perder a sus seres queridos. De este modo, se mencionarán nombres rescatados del olvido o menospreciados ante figuras de próceres masculinos. Durante mucho tiempo las mujeres peruanas han sido ignoradas como en todas las sociedades y países del mundo.

Una de las heroínas para el caso peruano es María Parado de Bellido, quien fue fusilada por los españoles al descubrirse que estaba vinculada al movimiento independentista. Esta heroína nace el 5 de julio de 1777 en Huamanga, según lo afirma Ricardo Palma en su Corona patriótica (2019). Se casó muy joven con Mariano Bellido y tuvieron siete hijos. Su historia de colaboración para la causa patriótica comienza cuando se vivía el entusiasmo por la llegada de San Martín y la expedición de Álvarez de Arenales. Estos hechos ocasionaron la organización de la población en montoneras o guerrillas para el apoyo de las fuerzas patrióticas.

Parado de Bellido era una mujer mayor para ese momento y buscaba una forma de contribuir al proceso independentista, dado que su hijo mayor y su esposo se habían encargado de ayudar militarmente, mientras que María optó por la vigilancia y el espionaje del ejército enemigo. Ambas tareas son fundamentales para tener conocimiento de las próximas acciones a realizar de los ejércitos, por lo cual el espionaje es determinante en una guerra. Asimismo, Mc Evoy (2020) resalta que existe un consenso entre varios autores respecto a la contribución femenina al movimiento independentista en cuestiones de inteligencia. Gracias al 
aporte de estas mujeres, los mensajes llegaban a oídos del bando patriota $y$, al mismo tiempo, podían difundir propaganda revolucionaria.

María no conocía la escritura ni sabía leer, al igual que muchas mujeres de su tiempo. Por este motivo necesitaba a alguien que la ayudara a comunicar los movimientos del Ejército realista mediante cartas. Consideramos que este esfuerzo para superar la barrera del lenguaje fue notable, dado que requería de otra persona para cumplir con su labor de espía, y probablemente demorara más en comunicar los mensajes que tenía para los patriotas organizados en montoneras. Esto último se debe a que en una revolución la comunicación escrita es fundamental para que sea exitosa.

Palma (2019) confirma su condición de iletrada.

Al tomar declaración a la Bellido sobre la carta, hallaron que no hablaba el idioma castellano ni menos podría escribirlo. Con este motivo creció el empeño de conocer al que había dado un aviso tan interesante y del que se había hecho un misterio en la ciudad, estando el secreto reducido a pocas personas (p. 19).

Cumpliendo con su labor, María informó al ejército patriota de una emboscada en la localidad de Quilcamachay el 29 de marzo de 1822. Al llegar los españoles a este lugar se frustran por la ausencia de personas, revisan arduamente toda la localidad y encuentran una de las cartas de la heroína. Descubierta y leída la misiva, los militares realistas mandan a capturarla para su posterior interrogación. Se le pidió que diga los nombres de las personas que la ayudaban a escribir las cartas. Fue torturada física y psicológicamente por orden del general Carratalá y aun así se negó a dar información sobre las personas involucradas (MC Evoy, 2020, p. 61). Además, la amenazaron con quemar su casa si seguía manteniendo silencio; sin embargo, se mantuvo firme en su decisión de guardar silencio.

La Bellido se negó constantemente a hacer la revelación, y prefirió la muerte a descubrir al que había vendido la confianza de los españoles. Aun en el momento mismo de ejecutarla, se la requirió ofreciéndola salvarla la existencia, pero ella insistió en su negativa y recibió la muerte con una firmeza inimitable, llevando su secreto a la tumba. Murió a la edad de 61 años. ¡Gloria a la heroína! (Palma, 2019, p. 19).

Tras notar la fuerte negativa de María, ordenaron exhibirla por la plaza para que las personas que quisieran levantarse en contra de la autoridad española supieran que ese sería su destino. Tras este acto, fue fusilada el 1 de mayo de 1822. No obstante, a pesar del heroísmo con el que había 
actuado Bellido, fue apartada de la historia durante mucho tiempo. Pereyra (2018) sostiene que se trató de ocultar inicialmente de la historiografía a esta mártir de la independencia debido a su origen, pues no se trataba de una mujer del entorno urbano, sino de distinta procedencia. Incluso para el siglo XIX y primeros años del siglo XX no era conocida con su verdadero nombre, sino se la llamaba por el nombre de su hija, Andrea Bellido. Fue en el gobierno de Leguía cuando se le reconoce como heroína y fue elevada al panteón de los héroes de la independencia. Se hizo una estatua en su nombre, tal como lo comunicó el entonces presidente en su mensaje al Congreso Nacional el 28 de julio de 1926: «Se ha inaugurado la estatua de la heroína nacional doña María Parado de Bellido en el parque que lleva su nombre, en Ayacucho. El monumento a Sucre está ya en camino a esa misma ciudad» (Leguía Salcedo, ante el Congreso Nacional, el 28 de julio de 1926, p. 32).

A pesar del actuar heroico de María en beneficio del ejército patriota y de la independencia del Perú, el Estado decimonónico solo se encargó de reconocer a los militares y la dejó de lado por su condición de mujer que residía en el espacio rural (Pereyra, 2018, p. 6).

Para el caso del Alto Perú, respecto a la participación femenina en las luchas independentistas, el 17 de mayo de 1812 un grupo de mujeres se alzaron frente al Ejército español, lideradas por una anciana que en su juventud había sido víctima de abusos por parte de los españoles. Así también, otra importante combatiente para este territorio fue Juana Azurduy, conocida como el Águila de las Batallas.

Azurduy fue hija de un español y de una madre indígena. Se sabe que desde joven organizaba reuniones secretas relacionadas con el levantamiento de Túpac Amaru II. Estando casada seguía organizando tertulias para debatir sobre política. En estas reuniones participaron figuras como Monteagudo, Castelli y Moreno, quienes posteriormente serían personajes relevantes en la Revolución de Mayo (D'Ambra, Espasande, Izuel y Pappalardo, 2020, p. 31). Junto con su esposo, Manuel Padilla, al iniciar la guerra en 1810 fundaron un movimiento de liberación, en el cual también participaron muchas mujeres. Todos ellos se levantaron en armas contra el dominio español. Además, Juana se encargaba de convencer a más pueblos de unirse a la causa. Tenía facilidad para comunicarse con ellos debido a su conocimiento del quechua y aimara.

Fue una mujer con un coraje inigualable. Sus cuatro hijos murieron en la guerra, pero luego de esto se embarazó nuevamente y entró en trabajo de parto en medio del campo de batalla. Ante aquella situación, puso a buen recaudo a su bebé recién nacida y luego continuó luchando en el enfrentamiento. Obtuvo el grado de coronela del ejército después 
de participar en una significativa batalla en 1816. Su ejército contaba con participación popular y estaba integrado por mujeres e indígenas.

Este hecho fue comentado por la misma Azurduy a Manuela Sáenz, en una carta escrita como respuesta a la «libertadora del Libertador» el 15 de diciembre de 1825. En ella relata con evidente emoción que el general Belgrano le mencionó que sería la segunda mujer en ganarse el grado de coronela, en referencia a Sáenz.

Señora doña Juana:

El Libertador Bolívar me ha comentado la honda emoción que vivió al compartir con el general Sucre, Lanza y el Estado Mayor del Ejército Colombiano, la visita que realizaron para reconocerle sus sacrificios por la libertad y la independencia. El sentimiento que recogí del Libertador, y el ascenso a coronel que le ha conferido, el primero que firma en la patria de su nombre, se vieron acompañados de comentarios del valor y la abnegación que identificaron a su persona durante los años más difíciles de la lucha por la independencia (Manuela Sáenz, Charcas, 8 de diciembre de 1825).

Señora Manuela Sáenz:

El 7 de noviembre, el Libertador y sus generales convalidaron el rango de teniente coronel que me otorgó el general Pueyrredón y el general Belgrano en 1816, y al ascenderme a coronel, dijo que la patria tenía el honor de contar con el segundo militar de sexo femenino en ese rango. Fue muy efusivo, y no ocultó su entusiasmo cuando se refirió a usted (Juana Azurduy, Cullcu,15 de diciembre de 1825).

Las citas anteriores corresponden a las cartas de ambas mujeres, quienes gozaron del título de coronela del ejército patriota. La primera cita es un extracto de la misiva de Manuela Sáenz, en la que felicita a Azurduy debido a que reconocieron sus sacrificios. Asimismo, le pide que la tenga como su amiga leal. Y la segunda, se trata de la respuesta de Azurduy, donde le indica que reconocieron su rango. No obstante, no todo fue felicidad y reconocimientos, puesto que su esposo muere tiempo después y los soldados realistas le cortan la cabeza con el objetivo de exhibirla. Frente a esto, Azurduy emprende una lucha para recuperar la cabeza de su esposo y así lo hizo el 15 de mayo de 1817. Asimismo, su participación en el proceso independentista fue resaltado por Manuel Belgrano, uno de los patriotas que impulsó la Revolución de Mayo, en una carta dirigida a Martín de Pueyrredón.

Paso a manos de V. E. el diseño de la bandera que la amazona doña Juana Azurduy tomó en el Cerro de la Plata como 11 leguas al este de Chuquisaca, en la acción que se refiere el comandante don Manuel Ascencio Padilla, quien no da esta gloria a la predicha su esposa por 
moderación, pero por otros conductos fidedignos consta que ella misma arrancó de manos del abanderado este signo de tiranía, a esfuerzo de su valor y de sus conocimientos en milicias poco comunes a las personas de su sexo (Belgrano, citado en D'Ambra, 2020, p. 72).

Sin embargo, al igual que Sáenz o Campusano, la tierra que ayudó a liberar se mostró indiferente, le fueron confiscados sus bienes y la pensión que le había otorgado Sucre le fue quitada en 1857. Juana murió en la pobreza en 1862 y fue enterrada en una fosa común. Ese fue el final de la heroína de la independencia del Alto Perú, después de perder a sus hijos y esposo mientras luchaba por la liberación del yugo español.

Otra de las mujeres relevantes en el espionaje por las luchas independentistas fue Policarpa Salavarrieta, una patriota colombiana nacida en un hogar de clase media. Su figura es rescatable ya que se conoce su participación en el Grito de Independencia del 20 de julio de 1810, siendo bastante joven. Además, fue una importante espía del bando independentista. Fue de gran ayuda a Simón Bolívar y Francisco de Paula Santander al organizar unidades militares; es decir, reclutaba jóvenes para que se unieran a las filas patrióticas. Empezó siendo tan solo una costurera, lo cual le permitió visitar muchos lugares de la ciudad y conocerlos a la perfección. Además, solía trabajar para familias realistas, lo que fue determinante en su labor de espía, porque podía escuchar datos y conversaciones de personajes realistas, y por su labor pasaba totalmente inadvertida. Luego toda la información recaudada era transmitida por ella misma a los patriotas.

En una de estas misiones fue detenida por el bando realista junto a Alejo Sabaraín, su gran amigo y compañero. Ambos fueron juzgados y posteriormente enfrentaron la sentencia de muerte por traición a la monarquía. Del mismo modo que María Parado de Bellido, fue torturada y se le pidió repetidas veces que brindara información de las identidades de los patriotas; no obstante, su decisión de protegerlos fue firme y no reveló ningún nombre. Policarpa fue fusilada el 14 de noviembre de 1817, cuando tenía tan solo 22 años. En las Memorias (1857) del general José Hilario López se relata lo que dijo al caminar hacia el lugar donde cumpliría su sentencia.

La Pola marchó con paso firme hasta el suplicio, y en vez de repetir lo que decían los ministros, no hacía sino maldecir a los españoles y encarecer su venganza. Al salir a la plaza y ver el pueblo agolpado para presenciar su sacrificio, exclamó: ¡Pueblo indolente! ¡Cuán diversa sería hoy vuestra suerte si conocieseis el precio de la libertad! Pero es tarde. Ved que, aunque mujer y joven, me sobra valor para sufrir mi muerte, y mil muertes más, y no olvidéis este ejemplo (p. 87). 
Es evidente la fortaleza de la Pola al aceptar su muerte firmemente con aquellas palabras que quedarían grabadas en la memoria de quien en algún momento fue el presidente de Colombia. No pudieron silenciarla ni minutos antes de morir; por el contrario, alentó al pueblo a seguir su ejemplo de luchar por la libertad, gritando que en algún momento tendrían su tan anhelada venganza. Al igual que la mártir peruana María Parado de Bellido, su heroísmo recién fue reconocido por el Estado colombiano en el siglo XX, exactamente en 1967. Así, el presidente Carlos Lleras Restrepo instituyó el 14 de noviembre, fecha de la muerte de la Pola, como el Día de la Mujer Colombiana, mediante la Ley 44, en honor a Policarpa Salavarrieta:

Artículo 1. La Nación se asocia a la conmemoración del sesquicentenario de la muerte de la heroína Policarpa Salavarrieta, fecha señalada históricamente el día 14 de noviembre de 1967.

Artículo 2. El Gobierno Nacional, por medio del Ministerio de Educación, el Ministerio de Defensa y la participación de la Academia de la Historia, se hará representar en los actos patrióticos que se celebrarán en aquella fecha, y tal día será proclamado cívico y Día de la Mujer Colombiana en todo el territorio nacional.

Otro de los reconocimientos que obtuvo tras su acción fue la inauguración de una estatua en el Perú en 1870, durante el gobierno de José Balta. El monumento se conocería con el nombre de la Estatua de la Libertad y tendría la imagen de Policarpa Salavarrieta. En suma, la Pola representa el símbolo de fortaleza y valentía de la mujer colombiana. Es una figura importante en la historia de la independencia del continente americano y prueba de que las mujeres, al igual que los hombres, entregaron su vida por la libertad de su tierra.

\section{Luchas femeninas desde la perspectiva masculina}

Para el proceso de independencia se nota un cambio en el discurso de los próceres respecto a las mujeres que participaron en las luchas independentistas, convencidos de su influencia e importancia en este contexto. Como se expuso en líneas anteriores, muchas mujeres contribuyeron a la causa como espías, entregando dinero, unas en el mismo campo de batalla y, en otras ocasiones, con su poder de convencimiento unían a más personas al ejército patriota. No obstante, debido a la visión que se tenía de la mujer en la época y las expectativas del rol que debía cumplir en la sociedad (quedarse en el espacio privado, la esfera doméstica y ser una buena madre y esposa), su valentía y contribución a la independencia del continente están ligadas en repetidas veces a lo masculino. 
Como ejemplo, se puede mencionar el caso de Bolívar, quien, al referirse con asombro a la cualidad de heroicidad de las mujeres, hace énfasis en que esta es una característica eminentemente masculina, por lo cual las considera «mujeres varoniles». Además, agradece a las matronas del Socorro, quienes participaron en la independencia de Colombia, y afirma que para tener esas fuerzas de luchar debieron «endurecer su tierno corazón» y que los españoles opresores «profanaron lo más inocente», es decir, «endurecieron» a las mujeres (Bolívar, 1820, citado en Valdivieso, 2009).

Ni Manuela Sáenz se salvó de estos calificativos, y dio a entender que por su coraje y valentía en la guerra cada vez era menos mujer. En una de sus cartas con Bolívar se menciona que el Libertador solía decirle que ella tenía más pantalones que cualquiera de sus oficiales. Nuevamente, la valentía era destinada a usarse para describir a los hombres de la época, y si una mujer también gozaba de esta característica, se consideraba que tenía atributos femeninos. Del mismo modo, Bolívar se refiere a ella como un «querido oficial» $y$ de temperamento viril:

siendo las 16:00 horas en punto, en otorgarle el grado de capitán de húsares; encomendándole a usted las actividades económicas y estratégicas de su regimiento, siendo su máxima autoridad en cuanto tenga que ver con la atención a los hospitales, y siendo este el último escaño de contacto de mis oficiales con la tropa. Cumplo así con la justicia de dar a usted su merecimiento de la gloria de usted congratulándome de tenerla a mi lado como mi más querido oficial del ejército colombiano. Su afectísimo, S. E. El Libertador (Bolívar, 2020, p. 40).

En el caso de San Martín, autoriza el uso de la Banda de Honor Blanca y Roja como galardón y una medalla de oro con una inscripción, cuyo fin era reconocer la labor femenina en la guerra. A pesar de estos reconocimientos en favor del género femenino, la ideología de exclusión de las mujeres no cambió considerablemente. En la primera Constitución peruana la gran mayoría no podía acceder a la ciudadanía por ser analfabetas.

El lugar de la mujer no estaba claramente determinado. El mismo Simón Bolívar no estaba preocupado por el apropiado lugar de las mujeres en las nacientes repúblicas, pero él definitivamente creía, como muchos pensadores de su tiempo, que las mujeres no pertenecían a la esfera pública de la política.

Además, se sabe que el hecho de que San Martín homenajeara a las heroínas patriotas con la banda bicolor ocasionó que la gran mayoría de hombres de la época estuviera en desacuerdo, puesto que consideraban que algunas de las mujeres no eran merecedoras de tal reconocimiento. 
Monteagudo fue uno de los principales personajes a quien causó desazón. Esto ocurrió debido a que creían que estas mujeres no tenían realmente un comportamiento patriota, sino todo lo contrario. Para ellos eran mujeres escandalosas haciendo referencia al comportamiento de Manuela Sáenz y su amorío con el Libertador caraqueño.

Entonces, era bastante evidente en la época que no había gran preocupación por la mujer. Ni siquiera los propios libertadores tenían en mente perpetuar el agradecimiento a las heroínas de la independencia. Al conocer el caso de Juana Azurduy, Rosa Campusano y Manuela Sáenz, se puede apreciar con bastante claridad cómo los reconocimientos se quedaron solamente en la ceremonia. Luego de ella, aquellas mujeres eran mal vistas y no se tomaba en cuenta su espíritu heroico ni patriota, sino que se intentaba manchar su actuar dirigiendo la atención hacia otras acciones y dejando que mueran en la indigencia.

Del mismo modo, para el general colombiano Santander las mujeres no debían participar en el campo de batalla. Decía que si alguien incumplía esa norma, sería severamente castigado. Sin embargo, sabemos que esta orden no fue respetada totalmente: «No marchará en la división mujer alguna, bajo la pena de 50 palos a la que se encuentre; si algún oficial contraviniere esta orden, será notificado con severidad, y castigado severamente el sargento, cabo o soldado que no la cumpla» (Santander, tomo I, 1969).

No obstante, para Manuel Belgrano la situación de la mujer en los Estados que se formaban era un tema de relevancia. Belgrano consideraba que debían ser educadas, porque eran quienes estaban encargadas de formar a los futuros ciudadanos de las naciones americanas. No se podía dejar simplemente que las mujeres estuvieran sometidas a la ignorancia (Morán, 2018, p. 154). Además, Belgrano redacta en el periódico Correo de Comercio (1810) su posición respecto a la educación femenina en la época, reconoce que no era adecuada y sostiene que de ello dependía el éxito o fracaso de la independencia. Por lo tanto, notamos cómo para Belgrano las mujeres constituyen parte fundamental del proceso independentista:

¿Y qué ha de enseñarles, si a ella nada le han enseñado? ¿Cómo ha de desarrollar las virtudes morales y sociales, las cuales son las costumbres que están situadas en el fondo de los corazones de sus hijos? ¿Quién le ha dicho que esas virtudes son la justicia, la verdad, la buena fe, la decencia, la beneficencia, el espíritu, y que estas calidades son tan necesarias al hombre como la razón de que proceden? (Correo de Comercio, Buenos Aires, nro. 21, 21 de julio de 1810). 
En el mismo sentido, el periódico peruano El Investigador del Perú (1813) considera que las mujeres debían tener acceso a una educación de calidad, puesto que, como creía Belgrano, en sus manos estaba el futuro de los nuevos ciudadanos de la patria. Debían brindarle los conocimientos que ellas mismas habían adquirido para que las futuras generaciones se nutrieran de ellas, para el beneficio común de la sociedad. De este modo, vemos cómo para algunos era necesario la reivindicación de la mujer en materia de educación.

Otra de las mujeres que fue víctima de los prejuicios de los hombres de su época fue Francisca Zubiaga, la Mariscala, quien rechazó el rol de mujer confinada en el interior del espacio doméstico para asumir una posición pública, que era de dominio masculino. Su figura como esposa del presidente resulta excéntrica para su tiempo, debido a que las mujeres no pertenecían a la esfera pública. Como escribió Valdelomar, la Mariscala es una de las más completas figuras en nuestra incipiente nacionalidad.

Gobernó a hombres, condujo ejércitos, sembró odios, cautivó corazones; fue soldado audaz, cristiana fervorosa; estoica en el dolor, generosa en el triunfo, temeraria en la lucha. Amó la gloria, consiguió el poder, vivió en la holgura, veló en la tienda, brilló en el palacio y murió en el destierro (Valdelomar, 2013, p. 11).

A pesar de los prejuicios de su época, Francisca Zubiaga, con trabajo y dedicación, conquistó la esfera pública dominada por hombres. Otro de los hechos que contribuyó a que las personas de su tiempo le prestaran mayor atención fue el recibimiento al Libertador Bolívar en el Cusco. Ella misma se encargó de coronarlo, debido a que su esposo era prefecto de dicha ciudad. Del mismo modo que con Manuela Sáenz, se hablaba de ella dirigiendo su atención a un supuesto amorío con Simón Bolívar y no a sus otras cualidades, como su faceta militar. No obstante, Zubiaga no dejaría que los chismes afectaran sus propósitos de obtener el máximo poder del Perú mediante su esposo Gamarra. Valdelomar, al igual que los autores mencionados anteriormente, retrata a esta mujer como «varonil»:

Comienza a manejar la pistola, el florete, la equitación. Asiste a los espectáculos más varoniles; se apasiona por las riñas de gallos, apuesta; le place el trato de varones; le interesa poco el de las damas, y comienza a ser el brazo director en los destinos de su marido. Ve de cerca el desastre de la patria, la anarquía la hiere, la dilapidación la indigna, y resuelve intervenir en los destinos de su país; es necesario que su marido sea presidente y ha de serlo. Ningún prejuicio es bastante fuerte para detenerla (Valdelomar, 2013, p. 40).

Tras asumir su esposo, Agustín Gamarra, la presidencia del Perú, la Mariscala fue duramente criticada por ejercer el poder directamente: 
mandaba cartas al Congreso sin que estas sean firmadas por su esposo y se decía que los ministros trabajaban con ella. Además, se encargaba de leer todos los documentos enviados por el Congreso. Si algo no le gustaba, simplemente lo borraba y reemplazaba por algo más agradable para ella. Por todo esto, la sociedad limeña acostumbraba a atacarla continuamente, e incluso le inventaban muchos amantes con el fin de desprestigiarla. No obstante, se sabe que Francisca Zubiaga solía rechazar a los hombres que se le acercaban con fines románticos. Era tan ambiciosa y determinada que el amor no era necesario ni suficiente para ella. Lo que quería era poder y eso ya lo había obtenido con el mariscal Gamarra:

¿Para qué necesito yo su amor? Su brazo, solo su brazo me hace falta. Vaya usted con sus suspiros, sus palabras sentimentales y sus romances donde las chiquillas. Yo no soy sensible sino a los suspiros del cañón, a las palabras del Congreso y a los aplausos y aclamaciones del pueblo cuando paso por las calles (Valdelomar, 2013, p. 69).

Era tanto su poder que logró que el vicepresidente La Fuente huyera del país. Esto porque Francisca creía que en algún momento llevaría a cabo un golpe de Estado, y se deshizo de todo aquel que se atreviera a conspirar contra ella y su esposo. A pesar de la opinión general de la sociedad peruana, los mandos militares apoyaban el actuar de la Mariscala, pero tiempo después la prensa empezó a manifestarse en su contra. También surgieron algunos levantamientos en oposición a la pareja presidencial y ambos huyeron en direcciones contrarias. Francisca partió con destino a Valparaíso, donde falleció al ser víctima de tuberculosis.

\section{Conclusiones}

En una sociedad en la cual la guerra y la política eran consideradas un asunto de hombres, la irrupción de la mujer en estos espacios fue visto inicialmente como un problema, pues lo que se esperaba de ellas era que cumplieran un buen rol de madre y esposa. Sin embargo, no todas las mujeres querían cumplir con aquellas expectativas y muchas participaron activamente en política desde jóvenes y ocuparon cargos militares. De este modo, las batallas por la independencia en América nos legaron las vivencias de un grupo de mujeres quienes pasaron a ser heroínas y mártires.

En primer lugar, destaca la figura de Manuela Sáenz, que se caracterizó por su coraje y valentía, ocupó el rango de coronela del ejército y contribuyó a la independencia de tres países. En su tiempo fue juzgada bajo los prejuicios propios de los hombres de su época, como Boussingault y Ricardo Palma, quienes afirmaban que Sáenz era una mujer con cualidades masculinas, una mujer viril por el hecho de estar rodeada 
de hombres y participar en el campo de batalla. Así también, resaltan Rosa Campusano y Juana Azurduy, quienes arriesgaron sus vidas por la causa independentista. Sin embargo, el reconocimiento brindado por los libertadores no duró para siempre y murieron en situación de indigencia, rogando para que los países que ayudaron a liberar les otorgaran una pensión digna de una heroína.

Además, merecen ser mencionadas dos mártires de la independencia: María Parado de Bellido y Policarpa Salavarrieta. Ambas aceptaron con entereza su muerte a manos de soldados realistas tras ser capturadas cuando se descubrió que realizaban tareas de espionaje para el ejército patriota, se enfrentaron a la pena de muerte por traición a la monarquía española y fueron fusiladas. Por último, la Mariscala también merece un espacio junto a estas mujeres que transgredieron las normas sociales impuestas por los hombres de su tiempo, ya que logró dominar el espacio masculino en una época en la cual se buscaba mantener a las mujeres en el espacio privado. En ese sentido, es evidente en la investigación la participación de la mujer en las guerras de independencia en América Latina y las constantes imágenes que sobre ellas se tuvieron en esos tiempos turbulentos y complejos de lucha por las legitimidades políticas.

\section{Contribución de autoría}

Daniel Morán y Monserratt Rivera han participado en la redacción y la aprobación de la versión final del artículo.

\section{Fuente de financiamiento}

Autofinanciado.

\section{Potenciales conflictos de interés}

Ninguno. 


\section{REFERENCIAS BIBLIOGRÁFICAS}

Azurduy, J. (15 de diciembre de 1825). Carta de respuesta a la coronela Manuela Sáenz, Cullcu.

Angulo, M. (2020). La presencia de académicas femeninas en los artículos de opinión de la prensa peruana. Desde el Sur, 12(2), pp. 607-612.

Bajini, I., Campuzano, L. y Perassi, E. (Eds.) (2013). Mujeres y emancipación de la América Latina y el Caribe en los siglos XIX y XX. Milán: Ledizioni.

Boussingault, J. B. (1985) Memorias. Bogotá: Banco de la República.

Correo de Comercio (21 de julio de 1810). Buenos Aires, nro. 21.

D’Ambra, D., Espasande, M., Izuel, M. y Pappalardo, G. (2020). Manuel Belgrano: desde la perspectiva del distanciamiento social obligatorio. Buenos Aires: Centro de Estudios de Integración Latinoamericana «Manuel Ugarte».

Editorial Luis Alberto Villamarín Pulido (1969). La campaña libertadora de 1819. Documentos históricos de Colombia. Tomo I. Nueva York: Luis Alberto Villamarín Pulido.

El Investigador (8 de agosto de 1813). Lima, nro. 39.

García, A. B. (2011). La participación de las mujeres en la independencia hispanoamericana a través de los medios de comunicación. Historia y Comunicación Social, 16, pp. 33-49.

García-Peña, A. (2016) De la historia de las mujeres a la historia del género. Contribuciones desde Coatepec, nro. 31.

Guardia, S. B. (Ed.) (2019). Micaela Bastidas. Lima: edición de la autora.

Guardia, S. B. (Ed.) (2014). Las mujeres en los procesos de independencia de América Latina. Lima: Centro de Estudios en la Historia de América Latina (Cemhal) y Organización de las Naciones Unidas para la Educación, la Ciencia y la Cultura (Unesco).

Guardia, S. B. (Ed.) (2013). Historia de las mujeres en América Latina. Lima: Centro de Estudios en la Historia de América Latina (Cemhal).

Guardia, S. B. (ed.) (2010). Las mujeres en la independencia de América Latina. Lima: Centro de Estudios en la Historia de América Latina (Cemhal), Universidad Particular San Martín de Porres (USMP) y Organización de las Naciones Unidas para la Educación, la Ciencia y la Cultura (Unesco).

Hortal, I. (2017). Mujeres ensayistas hispanoamericanas: una mirada entre identidad y género. Desde el Sur, 9(1), pp. 73-94. 
Leguía, A. B. (28 de julio de 1926). Mensaje del presidente del Perú, Augusto Bernardino Leguía Salcedo ante el Congreso Nacional. Recuperado de https://www.congreso.gob.pe/participacion/museo/congreso/mensajes/ mensaje_nacion_congreso_28_julio_1926

Ley 44 (20 de noviembre de 1967). Ley por la cual la Nación se asocia a la conmemoración del sesquicentenario del sacrificio de la heroína nacional Policarpa Salavarrieta. Diario Oficial, año CIV, nro. 32374.

López, J. H. (1957). Memorias del general José Hilario López, antiguo presidente de la Nueva Granada. Tomo primero. París: Imprenta de D'Aubusson y Kugelmann.

Martínez, F. (Ed.) (2012). Heroínas incómodas: la mujer en la Independencia de Hispanoamérica. Málaga: Ediciones Rubeo.

Mc Evoy, C. (2020). La mujer en el proceso de independencia del Perú. Revista Moneda del BCRP, 184, pp. 48-61.

Montiel, E. (2015). La mujer en la Independencia. Romper la conjura del silencio. Archipiélago, 22(87), pp. 14-16.

Morán, D. y Pérez, J. (2020). No solamente los nobles y los ricos, sino los plebeyos y mucha parte de las mujeres. El discurso político de la prensa chilena sobre la educación popular durante la Patria Vieja (1812-1814). Cuadernos de Historia, 53, pp. 229-253.

Morán, D. y Aguirre, M. (2013). La plebe en armas, la participación popular en las guerras de Independencia. Lima: Universidad Peruana Simón Bolívar.

Morán, D. (2018). Las «jacobinas de la revolución». Imágenes y representaciones de la mujer en la prensa de Buenos Aires (1810-1816). Tiempos Modernos, 37, pp. 148-160.

Morán, D. (2009). Élite y pueblo en la independencia en el Perú: estudios recientes de historia política, social y económica. Desde el Sur, 1(1), pp. 193-206.

Ortemberg, P. (2011). Apuntes sobre el lugar de la mujer en el ritual político limeño: de actrices durante el virreinato a actoras de la independencia. Estudios Interdisciplinarios de América Latina y el Caribe, 22(1), pp. 105-128.

Oviedo, M. Y. (2013) Manuela Sáenz en las Memorias de Jean Baptista Boussingault: ¿La mujer emancipadora o emancipada? En I. Bajini, L. Campuzano y E. Perassi (Eds.), Mujeres y Emancipación de la América Latina y el Caribe en los siglos XIX y XX. Milán: Ledizioni.

Palma, R. (2007). Tradiciones peruanas, séptima serie. Alicante: Biblioteca Virtual Miguel de Cervantes.

Palma, R. (2019) Corona patriótica. Islas Baleares: Textos.info. 
Pereyra, N. (2018). María Parado de Bellido y la Independencia en la región de Huamanga: representaciones de una heroína popular. Revista Historia de las Mujeres, XX(181).

Reisz, S. (2015). El rol de las mujeres en la independencia del Perú. Discurso para el proyecto «Bicentenario: Camino a la libertad». Recuperado de https://docplayer.es/21879588-El-rol-de-las-mujeres-enla-independencia-del-peru-susana-reisz-pucp.html

Rosas Lauro, C. (Ed.) (2019). Género y mujeres en la historia del Perú. Del hogar al espacio público. Lima: Fondo Editorial de la Pontificia Universidad Católica del Perú.

Sáenz, M. (8 de diciembre de 1825). Carta a la coronela Juana Azurduy, desde Charcas.

Sáenz, M. y Bolívar, S. (2010). Las más hermosas cartas de amor entre Manuela y Simón acompañadas de los Diarios de Quito y Paita, así como de otros documentos. Caracas: Ediciones de la Presidencia de la República.

San Martín, J. (2020). La participación de José de la Riva Agüero y Sánchez Boquete en el proceso de la independencia del Perú vista a través de sus memorias. Desde el Sur, 12(1), pp. 37-55.

Valdelomar, A. (2013) La mariscala, biografía novelada de doña Francisca Zubiaga de Gamarra. Lima: Grijalbo.

Valdivieso, M. (2009). Las mujeres y lo femenino en el discurso historiográfico: su contribución a la memoria y al imaginario social latinoamericano sobre la presencia de las mujeres en el espacio público. XII Jornadas Interescuelas, Departamentos de Historia, Departamento de Historia, Facultad de Humanidades y Centro Regional Universitario Bariloche. Universidad Nacional del Comahue, San Carlos de Bariloche.

Vargas, J. L. (2019). Rosa Campusano, la Protectora. Diario Oficial El Peruano, Lima. 